\title{
S3 Fig:
}

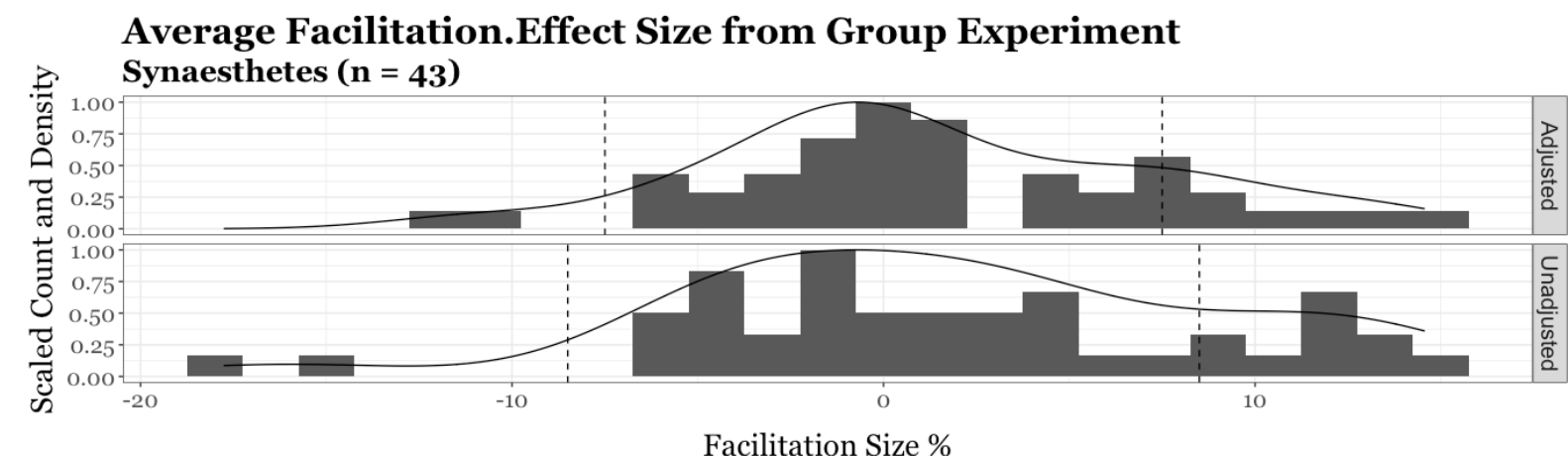

Supplementary Figure 3: Scaled Histogram and Kernel Density estimates of Facilitation Effect sizes (adjusted and unadjusted) for synaesthetes $(n=43)$ from the Group Experiment. The columns outside the dotted lines represent the top quartile (by magnitude) of participants. 